\title{
Bilateral Ovariectomy Decreases the Levels of Cyclic Nucleotides and Nuclear Phosphorylated Estrogen Receptor-Alpha in Memory-Sensitive Rat Brain Regions
}

\author{
Ahsas Goyal, Debapriya Garabadu* \\ Division of Pharmacology, Institute of Pharmaceutical Research, GLA University, Mathura, Uttar Pradesh, INDIA.
}

\begin{abstract}
Aim/Background: The level of phosphorylated Estrogen Receptor alpha (ER $\alpha$ ) in the nucleus was investigated in different memory-sensitive brain regions of estrogendeficient female rats. Further, the levels of cyclic nucleotides were estimated in those brain regions to draw a possible correlation with phosphorylated ER $\alpha$ signaling. Materials and Methods: Bilateral ovariectomy was performed on the first day of the experimental schedule of 60 days. Behavioural analysis was performed and various biochemical parameters were assessed in discrete brain regions of rat. Results: Ovariectomy caused a significant deterioration in learning and memory of the animals in terms of increase in transfer latency, decrease in time spent and percentage of total distance traveled in the target quadrant in Morris Water Maze (MWM) test protocol. Further, ovariectomy reduced the spontaneous alteration behavior of the rats in the $\mathrm{Y}$-maze test. There was a significant increase in cholinergic dysfunction in respect of decrease in the activity of choline acetyltransferase and level of acetylcholine and an increase in the activity of acetylcholinesterase in rat hippocampus, pre-frontal cortex and amygdala. Subsequently, ovariectomy significantly reduced the extent of phosphorylation and translocation of ER $\alpha$ in such rat brain regions. Moreover, ovariectomy caused a decrease in the levels of cyclic nucleotides such as CAMP and cGMP in these rat brain regions. Additionally, there was a significant positive correlation between the ratio of cyclic nucleotides (cGMP/cAMP) and nuclear $\mathrm{p}$-ER $\alpha$ in all brain regions of these ovariectomized animals. Conclusion: The cyclic nucleotides could be a potential and alternate target to promote the phosphorylated ER $\alpha$ receptor-mediated mechanism during memory formation in estrogen deficiency condition.
\end{abstract}

Key words: Bilateral ovariectomy, Estrogen receptor alpha (ER $\alpha)$, Cyclic nucleotides, Ligand-independent mechanism, Cholinergic activity, Memory.

\section{INTRODUCTION}

Cognitive dysfunction is the loss of intellectual skills like perception, acquisition, comprehension and response to information presented to a person. This may influence the thinking, memory and reasoning capabilities of a person. ${ }^{1}$ Dementia is considered as one of the neuropsychological hallmarks of cognitive dysfunction. ${ }^{2}$ It is estimated that dementia may be prevalent in approximately 81.1 million of world population by 2040. ${ }^{3}$ Further, it has also been suggested that the incidence of dementia is higher in females than males in the world population. ${ }^{4}$ Literature suggests that the risk of dementia is higher in post-menopausal women than pre-menopausal females. ${ }^{5}$ It is well accepted that during menopause condition estrogen level becomes deficit, which may lead to several pathological alterations in the brain, including synaptic damage, neuroinflammation and neuronal cell death. ${ }^{6}$ In addition to the clinical study, experimental research suggests that estrogen deficiency is one of the plausible factors in the genesis of several
Submission Date: 02-08-2019; Revision Date: 03-10-2019; Accepted Date: 06-11-2019 DOI: 10.5530/ijper.54.1.15 Correspondence: Dr. Debapriya Garabadu, Associate Professor, Division of Pharmacology, Institute of Pharmaceutical Research, GLA University, Mathura, 281406, Uttar Pradesh, INDIA.

Phone: +918853139229

E-mail: debapriya.garabadu@gla.ac.in

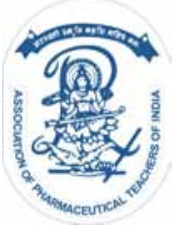

www.ijper.org 
neurodegenerative disorders, including Alzheimer's Disease (AD). ${ }^{7,8}$ Therefore, it is imperative to establish the mechanism of estrogen in the pathogenesis of neurodegenerative disorders such as AD.

Estrogen exhibits physiological function through classical estrogen receptor alpha $(\mathrm{ER} \alpha)$-mediated genomic mechanism to promote neuronal growth and synaptic plasticity and thus strengthens cognitive function. ${ }^{9}$ Classically, liganded $\mathrm{ER} \alpha$ dimerizes and translocate to the nucleus, acts in itself as transcription variables, binds to particular promoter components for Estrogen Reaction (ERE) or interacts with other protein-protein variables for transcription. ${ }^{10,11}$ In addition, unliganded ER $\alpha$ is also phosphorylated by activated kinases, then dimerize, bind DNA and regulate gene transcription. ${ }^{12}$ These observations indicate the fact that an additional signaling pathway could be an important mediator to regulate estrogen-dependent activity in physiological conditions. Experimental reports suggest that the level of expression of $E R \alpha$ is decreased in several memory-sensitive brain regions in neurodegenerative disorders, including AD. ${ }^{13,14}$ Moreover, it has also been documented that long-term deprivation of estrogen after ovariectomy leads to a significant decrease in brain ER $\alpha$ expression. ${ }^{15}$ It is well established that the reduced expression level of $\mathrm{ER} \alpha$ is associated with cholinergic dysfunction with respect to the decreased expression level of muscarinic receptors in memory sensitive brain regions such as the hippocampus. ${ }^{16}$ However, there is a lack of report on the phosphorylated ER $\alpha$-mediated effect in cholinergic dysfunction associated cognitive decline during estrogen deficiency condition.

It has been documented that cyclic nucleotides are considered as one of the downstream molecules of ER $\alpha$ mediated signaling mechanisms in memory-sensitive brain regions. ${ }^{17}$ These cyclic nucleotides control several cell functions in signal transduction and synaptic neuron transmission in the central nervous system. ${ }^{18,19}$ Literature reports suggestes that both Cyclic Adenosine Monophosphate (cAMP) and cyclic Guanosine Monophosphate (cGMP) signaling regulates the extent of memory formation. ${ }^{20,21}$ Moreover, a decrease in the cAMP and cGMP concentrations is reported in estrogen deficiency condition in the animal models. ${ }^{22,23}$ It is well accepted that muscarinic receptors exhibit their intrinsic activity through cyclic nucleotide-mediated cellular mechanisms. ${ }^{24} \mathrm{~A}$ report suggests that there is a decrease in cyclic nucleotides along with the decreased expression of both ER $\alpha$ and muscarinic receptors in memory sensitive brain regions of estrogen-deficient animals. ${ }^{16,24}$ Hence, there is a lack of correlation between the level of cyclic nucleotides and the phosphorylated ER $\alpha$ - mediated signaling in the cholinergic dysfunction associated cognitive decline during estrogen deficiency condition.

Therefore, the present study explored the extent of phosphorylation and translocation of $\mathrm{ER} \alpha$ receptor in memory-sensitive brain regions of bilateral ovariectomy challenged female rats. Further, the levels of cyclic nucleotides (cAMP and cGMP) were estimated in memory-sensitive brain regions of such animals. Moreover, a correlation analysis was performed to establish a relationship between the ratio of cyclic nucleotides (cGMP/cAMP) and nuclear p-ER $\alpha$ in memory-sensitive brain regions of the rodents.

\section{MATERIALS AND METHODS}

\section{Animals}

Female Wistar rats of 250-280 gm were acquired and used in the research from Animal House of Institute of Pharmaceutical Research, GLA University, Mathura. The animals were grouped and housed in optimum condition of $22-26^{\circ} \mathrm{C}$ temperature, $45-55 \%$ relative humidity and $12 \mathrm{hr}$ light: $12 \mathrm{hr}$ dark cycle in polyacrylic cages lined with husk. Animals were permitted to feed their standard soya-free chow diet and water ad libitum freely. All the experimental processes used have been carried out under the strict complying rules of Committee for the Purpose of Control and Supervision of Experiments on Animals (CPCSEA) under the authorization of the Institutional Animal Ethics Committee (GLAIPR/CPCSEA/IAEC/P'Col/2015/01).

\section{Chemicals}

The ER $\alpha$, phosphorylated ER $\alpha, \beta$-actin and histone-3 (H3) antibodies were procured from Abcam Plc., Cambridge, USA. All the chemicals and reagents were of analytical grade and purchased from local suppliers.

\section{Experimental Design}

The rats were accustomed and grouped into three of six animals each, named as Control, Sham (subjected to bilateral incisions without removing the ovaries) and OVX. Animals of all groups except the control group were anesthetized using pentobarbitone (45 mg/ $\mathrm{kg}$ i.p.) and then ovariectomized under aseptic conditions. ${ }^{15}$ Cleaning of the cages and wounds disinfection was performed on a daily basis. The entire experimental protocol was followed for 60 days. The rats were exposed to Morris Water Maze (MWM) test paradigm for 5 consecutive days, i.e., from Day-56 to Day-60 of the experimental schedule. Subsequently, on Day-60 the animals were exposed to Y-maze test after $30 \mathrm{~min}$ 
to MWM test. The behavioral activities were recorded and measured in ANY-maze ${ }^{\mathrm{TM}}$ (Version-4.96, USA) video-tracking system. The serum level of estradiol of the animals was estimated on Day-1 before ovariectomy and on Day-60 of the experimental protocol using the manufacturer's instruction of standard assay kit (Abcam Pvt. Ltd., ab108667). All the animals were killed by decapitation after the successful behavioral performance. The uterus and brains of all animals were taken and further, the brains were microdissected $^{25}$ into the HIP, PFC and AMY for estimating the biochemical parameters. The diagrammatic representation of the experimental schedule was depicted in Figure 1.

\section{Induction of bilateral ovariectomy}

Female Wistar rats were anesthetized on their dorsal surface and the area of the surgery was shaved and cleaned with ethanol. A transverse peritoneal incision of $0.4-0.6 \mathrm{~cm}$ was made using a surgical scalpel blade on the middle part of the left and right dorsal side of flanks to induce bilateral ovariectomy. Ovaries were pulled out and removed from both sides. The uteri on both sides were pushed back and incisions were sutured in layers (muscle and skin) using absorbable suture (Ethicon chromic sutures, Johnson and Johnson Ltd., India). Neomycin antibiotic powder was applied twice daily on wounds for one week. Throughout the operation, the high degree of aseptic procedure was retained and animals were permitted to recover. The rats were housed separately in cages after surgery, provided for a period of one week with clean and dry bedding sets. ${ }^{15}$

\section{Evaluation of Cognitive Deficits in Different Behavioural Models}

Morris Water Maze (MWM) Test for Assessing Learning and Memory

The MWM test is frequently used to assess learning and memory using animal models. ${ }^{26,27}$ The protocol was carried out on the concept of placing the animal in a large water pool separated into four equal quadrants. The tendency of the animals was to find a hidden escape platform achieved its inclination to escape. Four consecutive days of practice (with a gap of $5 \mathrm{~min}$ in between), each animal was subject to a quest for a hidden platform for four consecutive days. A video camera and a tracking system registered the escape latencies (time required to reach the platform as a goal; Day-56 to Day-59), a mean time spent by the animals in target quadrant, percentage of total distance traveled in target quadrant and swimming speed (Day-60) for each animal (ANY-maze video tracking system, Stoelting Co., Version-4.96, USA). The Day-59 escape latency time was taken as the acquisition or learning index to find the hidden platform in the water maze. The hidden platform has been removed on Day-60. Each rodent was permitted to explore the pool only for $120 \mathrm{~s}$. The mean time spent in all the quadrants in search of the hidden platform was recorded. The animal's mean time spent in the target quadrant was taken as the recovery or memory index. The experiment was in the same place at all times. Care was taken with regard to the relative place of the MWM with regard to other artifacts in the laboratory in order not to disturb prominent visual indications during the entire length of the research.

\section{Y-Maze Test for Assessing Spontaneous Alteration Behaviour}

On Day-60, working memory in Y-Maze for spontaneous alteration behavior (SAB) was assessed. ${ }^{28}$ The device was a black painted wooded horizontal labyrinth $\left(40 \times 3 \times 12 \mathrm{~cm}^{3}\right)$ with three arms (A, B and C labelled) arranged at an angle of $120^{\circ}$ to each other. Each animal was placed in the middle of the apparatus. The animal was allowed to move freely for 8 min through the maze. The number of alterations (i.e., consecutive sequences of entry of $\mathrm{ABC}, \mathrm{CAB}$ or $\mathrm{BCA}$, but not $\mathrm{BAB}$ ) and total arm entries were recorded. The arms were thoroughly cleaned with water spray to remove residual odor in between the tests. The percentage alteration was calculated according to the following equation: percentage alteration $=[($ number of alterations $) /($ total arm entries-2)] x 100.

\section{Assessment of the Cholinergic Dysfunction The Method of Sample Preparation}

The brain tissues were homogenized with a homogenizer containing $1 \mathrm{ml}$ of $0.1 \mathrm{M}$ perchloric acid. Homogenate was stored and thereafter $50 \mu \mathrm{l}$ of $4 \mathrm{M}$ potassium acetate was mixed to modify the $\mathrm{pH}$ to 4.0 which was followed by centrifugation at $4000 \mathrm{~g}$ for 15 min. $^{29}$

\section{Assay of ChAT activity}

The levels of ChAT were determined spectrophotometrically at $450 \mathrm{~nm}$ using an enzyme-linked immuno-

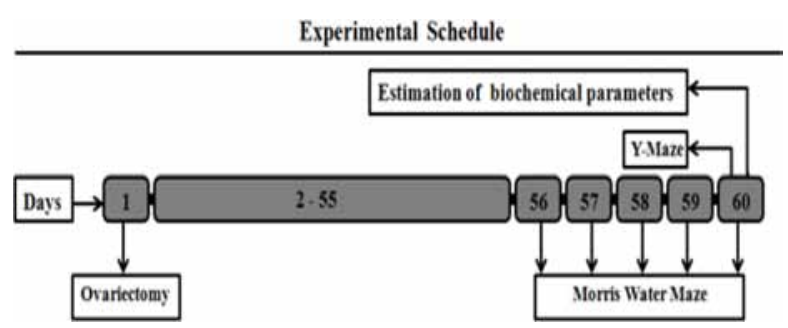

Figure 1: Experimental procedure. 
sorbent assay kit (SEB929Mu; Wuhan, Hubei, China) according to the manufacturer's instructions.

\section{Evaluation of ACh level}

The quantity of ACh in brain tissue was estimated with the use of Amplex red assay kit (Molecular Probes, Inc., USA) following the procedure of Zoukhri and Kublin. ${ }^{30}$ The fluorescence was recorded at $530 \mathrm{~nm}$ excitation and $590 \mathrm{~nm}$ wavelengths with help of spectrofluorometer. A standard protocol was used to determine the protein content. ${ }^{31}$

\section{Evaluation of Activity of AChE}

The increase in the activity of AChE is regarded as an indicator of the loss of cholinergic neurons in brain tissue. The activity of AChE was evaluated in assay kit of Amplex red AChE (Molecular Probes, Inc., USA). The fluorescence was determined at $530 \mathrm{~nm}$ excitation wavelength and $590 \mathrm{~nm}$ emission wavelength with the assistance of spectrofluorometer. The Lowry method was used to determine protein content. ${ }^{31}$

\section{Estimation of Cyclic AMP (cAMP) and Cyclic GMP (cGMP) levels}

Intracellular levels of cyclic nucleotides (cAMP and cGMP) in tissue were determined using direct cAMP (ab133051; Abcam Plc., Cambridge, USA) and cGMP (ab133052; Abcam Plc., Cambridge, USA) enzyme immunoassay kit according to the manufacturer's instruction. Results were expressed as $\mathrm{pmol} / \mathrm{mg}$ protein.

\section{Immunoblotting}

The tissues were subjected to lysis in a buffer comprising full protease inhibitor cocktail for protein analysis. Subsequently, tissues were subjected to homogenization in a Potter-Elvehjem homogenizer and thereafter the homogenate was centrifuged at $1500 \mathrm{~g}$ for 15 min. The post-nuclear fraction was then centrifuged at $100000 \mathrm{~g}$ for $60 \mathrm{~min}$. The resulting supernatant was considered as the cytosolic fraction. Concentrations of proteins were determined by the standard technique in each fraction. ${ }^{32}$ A standard plot was made using bovine serum albumin. An aliquot of each cytoplasmic sample was electrophoresed on 10\% SDS-PAGE gels for $\mathrm{ER} \alpha$ and phosphorylated $\mathrm{ER} \alpha$ proteins. It was then transferred to polyvinylidene fluoride membranes and probed with specific antibodies. Similarly, an equal aliquot of each nuclear sample was electrophoresed on $10 \%$ SDS-PAGE gels for phosphorylated $\mathrm{ER} \alpha$ proteins, transferred to polyvinylidene fluoride membranes and probed with specific antibodies. The membrane was incubated overnight with rabbit anti-ER $\alpha$ (Abcam Plc., Cambridge, USA; ab3575) and anti- phosphorylated
ER $\alpha$ (Abcam Plc., Cambridge, USA; ab131111, phospho S106) polyclonal primary antibody at a dilution of 1:1000 and 1:100 respectively. The membrane was stripped with stripping buffer ( $25 \mathrm{mM}$ Glycine $\mathrm{pH}$ 2.0, $2 \%$ SDS for $30 \mathrm{~min}$ at room temperature) after treatment with the secondary antibodies of ER $\alpha$ and phosphorylated $\mathrm{ER} \alpha$. Thereafter, it was again probed with rabbit anti- $\beta$-actin and anti-histone-3 (H3) polyclonal primary antibody at a dilution of 1:500 and 1:1000 to confirm equal loading of protein in cytoplasmic and nuclear fraction respectively. The secondary antibodies of either $\beta$-actin or $\mathrm{H} 3$ were used to probe the membrane. The enhanced chemiluminescence (ECL) reagents (Amersham Bioscience, USA) were used to detect the Immunoreactive band of proteins. The quantitative analysis was estimated by a densitometric scan of films. The densitometric analysis was used to calculate the area of immunoreactive band using Biovis gel documentation software.

\section{Analysis of Data}

All the data were represented as mean \pm Standard Error of the Mean (SEM). Repeated measures of two-way analysis of variance (ANOVA) followed by Bonferroni Post hoc test was used for statistical analysis for body weight, estradiol level and escape latency of the animals. All other statistical analyses were done using one-way ANOVA followed by Student Newman-keuls Post-hoc test. $P<0.05$ was considered significant. In addition, Pearson's correlation analysis was performed to correlate between the ratio of cyclic nucleotides (cGMP/cAMP) and nuclear p-ER $\alpha$ with respect to $\mathrm{H} 3$ in the HIP, PFC and AMY of the animals. In correlation analysis, the criterion for statistical significance was $P<0.05$.

\section{RESULTS}

\section{Effect of bilateral ovariectomy on body weight, estradiol level and uterus weight}

The effect of ovariectomy on body weight, estradiol level and uterus weight is depicted in Figure 2. There were significant differences in body weight and estradiol level of the animals among group $([\mathrm{F}(2,30)=4.2$, $P<0.05]$ and $[\mathrm{F}(2,30)=13.7, P<0.05]$ respectively $)$ and day $([\mathrm{F}(1,30)=34.7, P<0.05]$ and $[\mathrm{F}(1,30)=17.8$, $P<0.05]$ respectively). Further, there was significant interaction between group and day in the body weight as well as in the level of estradiol of the animals $([\mathrm{F}(2,30)=5.2, P<0.05]$ and $[\mathrm{F}(2,30)=7.7, P<0.05]$ respectively). Bonferroni test showed that there were no significant differences in body weight and level of estradiol in the blood of the animals among different groups 


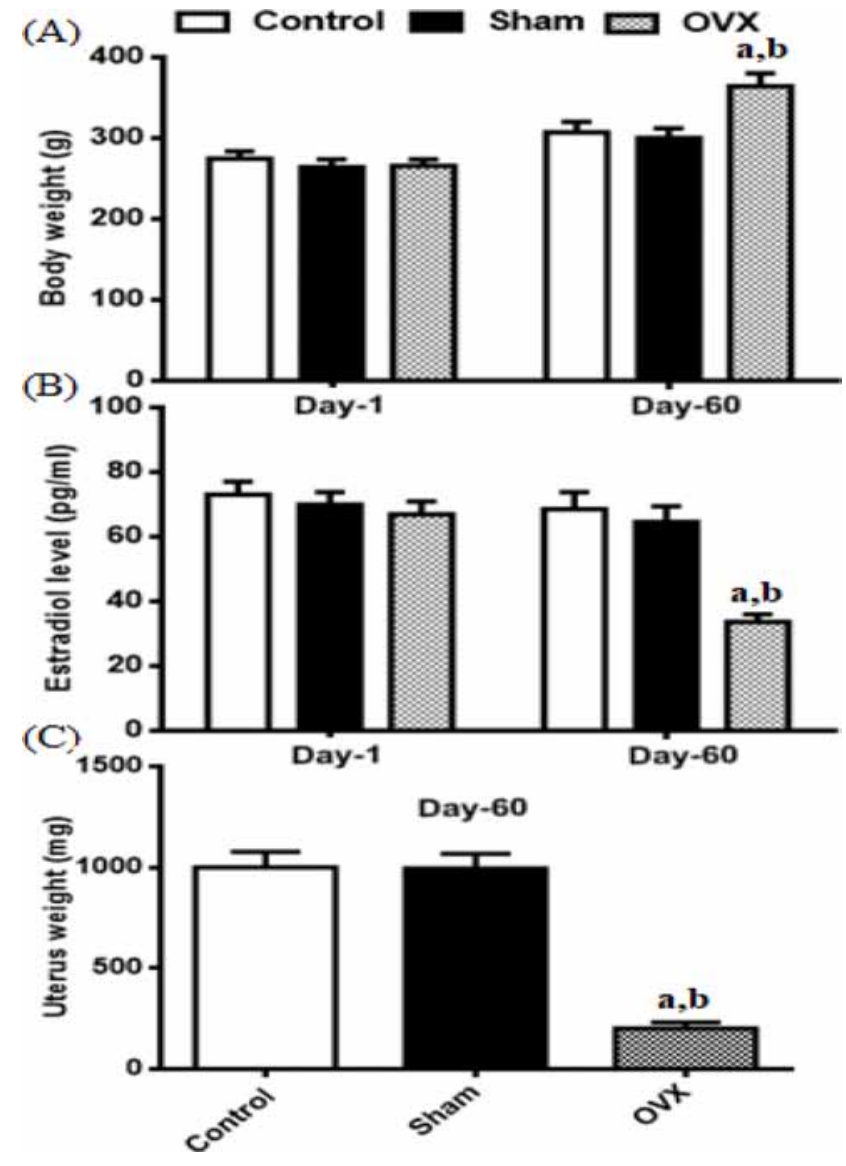

Figure 2: Effect of bilateral ovariectomy-induced changes in body weight (A), estradiol level (B) and uterus weight (C). All values are expressed in mean $\pm \operatorname{SEM}(n=6)$. ${ }^{\text {a }} P<0.05$ as compared to Control, ${ }^{b} P<0.05$ as compared to Sham (Repeted measures of Two-way ANOVA followed by Bonferroni's multiple comparison test for body weight and estradiol level and one-way ANOVA followed by Student-Newmann-Keuls post hoc test for uterus weight among groups).

on Day-1 of the experimental schedule. OVX challenged rats exhibited a significant increase and decrease in body weight and estradiol level compared to other group animals on Day-60, respectively. It was indicating that there was gain in body weight and loss in the level of estradiol of the animals due to OVX paradigm.

There were also significant differences in the uterus weight of animals among the group $[\mathrm{F}(2,15)=52.9$, $P<0.05]$. Post-hoc test showed that OVX significantly decreased the uterus weight compared to Control and Sham group animals.

Bilateral OVX attenuated learning and memory formation of the animals in MWM test

Figure 3 illustrates the effect of OVX on alteration in escape latency period from Day-56 to Day-59 (A), the time spent in the target quadrant (B), the percentage of total distance travelled in the target quadrant $(\mathrm{C})$ and swimming speed of the animals in Day-60 (D) during
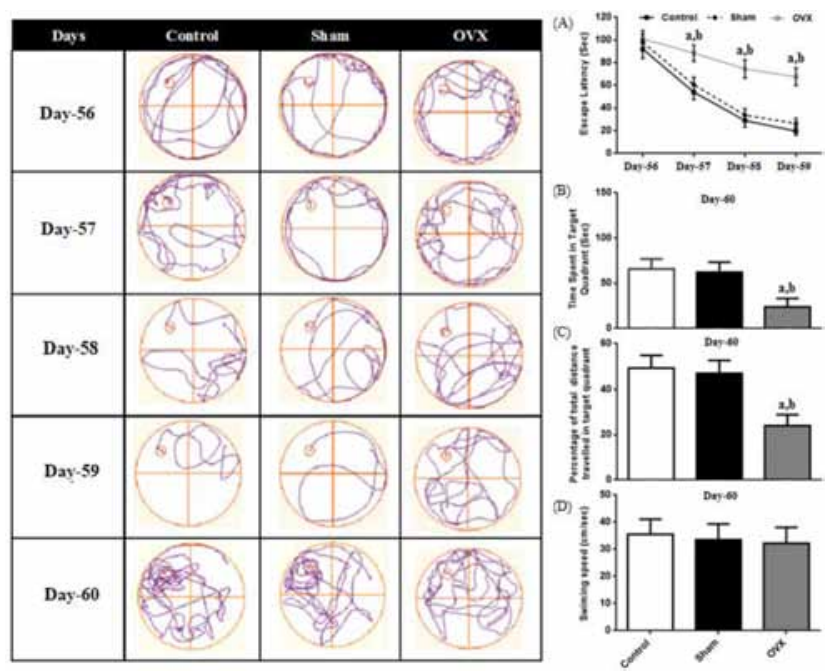

Figure 3: Effect of bilateral ovariectomy-induced changes in the learning and memory of rats in Morris Water Maze (MWM). The table left side of the figure represents a representative track plot of each animal of all the groups at every time point of the experimental schedule. Connecting lines represent the changes in escape latency from Day-56 to Day-59 (A) and the bar diagrams represent the time spent in target quadrants (B), percentage of total distance traveled in the target quadrant (C) and swimming speed (D) in Day-60. All values are expressed in mean \pm SEM $(n=6)$. ${ }^{\mathrm{P}}<0.05$ as compared to Control, ${ }^{b} P<0.05$ as compared to Sham (Repeted measures of Two-way ANOVA followed by Bonferroni's multiple comparison test for escape latency and one-way ANOVA followed by Student-Newmann-Keuls post hoc test for the time spent in target quadrants and percentage of total distance traveled in target quadrant).

MWM test paradigm. Statistical analysis showed that there were significant differences in the escape latency period among group $[\mathrm{F}(2,60)=30.1, P<0.05]$ and day $[F(3,60)=47.2, P<0.05]$. Further, there was a significant interaction between group and day in the escape latency of the animals $[F(6,60)=2.4, P<0.05]$. Bonferroni test showed that there were no significant differences in the escape latency of the animals among the group on Day-56 of the MWM test. Interestingly, rats of OVX group exhibited higher escape latency compared to Control and Sham group animals on Day-57 of the MWM test protocol indicating that there was loss in learning abilities of the animals due to OVX paradigm. Moreover, a similar observation was recorded in the animals up to Day-59 of the test.

One-way ANOVA revealed that there were significant differences in the time spent in the target quadrant $[\mathrm{F}(2,15)=29.5, P<0.05]$ and percentage of total distance traveled in target quadrant $[\mathrm{F}(2,15)=40.2, P<0.05]$ of the animals in Day-60 during MWM test. However, there was no significant difference in swimming speed $[F(2,15)=0.50, P>0.05]$ of the animals among groups. Post-hoc test showed that OVX significantly reduced 


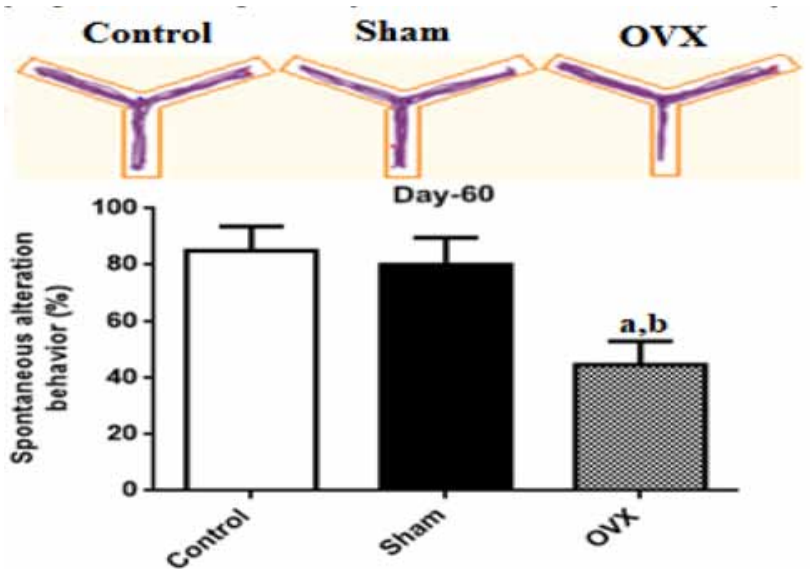

Figure 4: Effect of bilateral ovariectomy-induced changes in spatial memory in terms of spontaneous alteration behavior of rats in the $\mathrm{Y}$-maze test. All values are expressed in mean \pm SEM $(n=6)$. ${ }^{\text {a }} P<0.05$ as compared to Control, ${ }^{\mathrm{b}} P<0.05$ as compared to Sham (One-way ANOVA followed by Student-Newmann-Keuls post hoc test).

the amount of time spent and percentage of total distance traveled in the target quadrant of the animals in Day-60 of the test than Control and Sham group rodents indicating the fact that OVX significantly caused a loss in memory formation of the animals in the test.

\section{Bilateral OVX reduced spatial memory formation of the animals in the Y-maze test}

The effect of OVX on changes in the SAB of the rats in the Y-maze test is represented in Figure 4. There were significant differences in the $\mathrm{SAB}[\mathrm{F}(2,15)=$ $36.2, P<0.05]$ of the animals among groups. Post-hoc test showed that OVX challenged rats exhibited a significant decrease in the $\mathrm{SAB}$ behavior during $\mathrm{Y}$ - maze test compared to Control and Sham group animals indicating the fact that OVX significantly reduced the spatial memory formation in terms of $\mathrm{SAB}$ of the rodents during the paradigm.

\section{Bilateral ovariectomy caused cholinergic dysfunction in discrete brain regions}

The effect of bilateral ovariectomy on ACh level and activities of ChAT and AChE in HIP, PFC and AMY are depicted in Figure 5. There were statistical differences in the ACh level and activities of ChAT and AChE in HIP $([\mathrm{F}(2,15)=48.5, P<0.05],[\mathrm{F}(2,15)=43.9, P<0.05]$ and $[F(2,15)=30.1, P<0.05]$ respectively), PFC $([\mathrm{F}(2,15)=73.0, P<0.05],[\mathrm{F}(2,15)=20.6, P<0.05]$ and $[\mathrm{F}(2,15)=42.3, P<0.05]$ respectively) and AMY $([\mathrm{F}(2,15)=152.0, P<0.05],[\mathrm{F}(2,15)=18.8, P<0.05]$ and $[F(2,15)=31.6, P<0.05]$ respectively) among groups. Post-hoc test showed that ovariectomy decreased the level of ACh and activity of ChAT in all the brain regions compared to control and sham group animals.

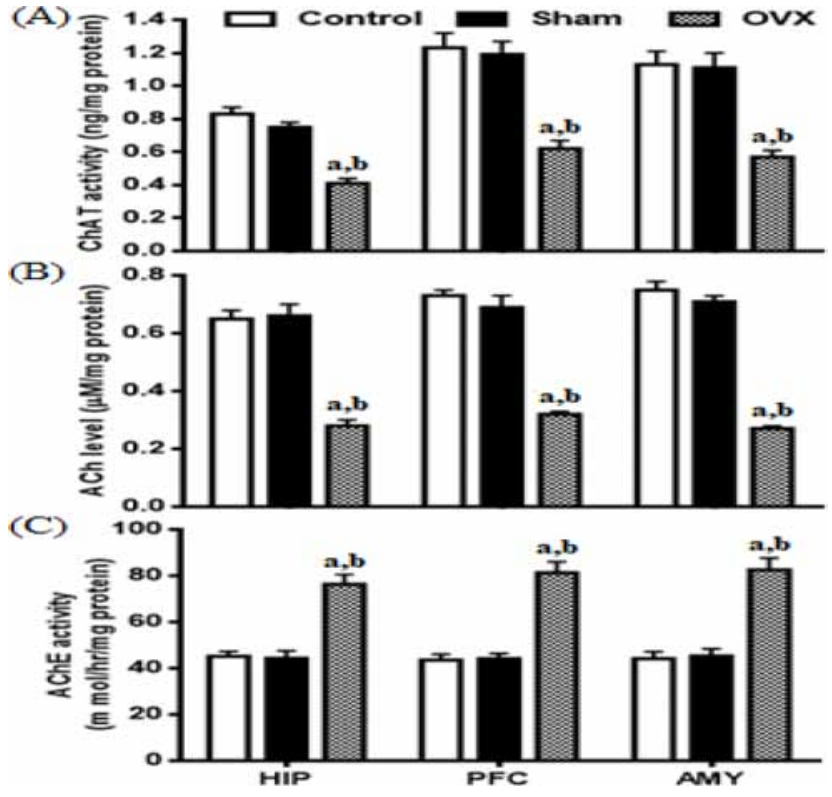

Figure 5: Effect of bilateral ovariectomy-induced changes in cholinergic function in terms of the activity of ChAT (A), level of ACh (B) and activity of AChE (C) in rat HIP, PFC and AMY. All values are expressed in mean $\pm \operatorname{SEM}(n=6)$. ${ }^{\text {a }} P<0.05$ as compared to Control, ${ }^{b} P<0.05$ as compared to Sham (One-way ANOVA followed by Student-Newmann-Keuls post hoc test).

However, ovariectomy increased the activity $\mathrm{AChE}$ in all the brain regions compared to all other groups of rats.

\section{Ovariectomy decreases the levels of cyclic nucleotides in discrete brain regions}

Figure 6 illustrates the effect of ovariectomy on the levels of cAMP, cGMP and their ratio (cGMP/cAMP) in rat HIP, PFC and AMY. There were statistical differences in the levels of cAMP and cGMP and cGMP / cAMP ratio in HIP $([\mathrm{F}(2,15)=30.5, P<0.05]$, $[\mathrm{F}(2,15)=59.5, P<0.05]$ and $[\mathrm{F}(2,15)=42.5, P<0.05]$ respectively), $\mathrm{PFC}([\mathrm{F}(2,15)=13.2, P<0.05],[\mathrm{F}(2,15)$ $=77.2, P<0.05]$ and $[\mathrm{F}(2,15)=52.5, P<0.05]$ respec tively) and AMY ([F $(2,15=21.6, P<0.05],[\mathrm{F}(2,15)$ $=85.1, P<0.05]$; and $[\mathrm{F}(2,15)=76.1, P<0.05]$ respectively) among groups. OVX significantly decreased the levels of cAMP and cGMP and cGMP/cAMP ratio in all the brain regions of rats compared to control and sham group animals in Post-hoc test.

\section{Ovariectomy attenuates the extent of phosphorylation and translocation of p-ER $\alpha$ receptor in discrete brain regions}

Figure 7 illustrates the effect of OVX on the extent of phosphorylation of $\mathrm{ER} \alpha$ receptors in cytoplasm and translocation of $\mathrm{p}-\mathrm{ER} \alpha$ receptor in the nucleus in discrete brain regions. There were significant differences in the extent of phosphorylation of ER $\alpha$ receptor in cytoplasm and translocation of $\mathrm{p}-\mathrm{ER} \alpha$ receptor in 


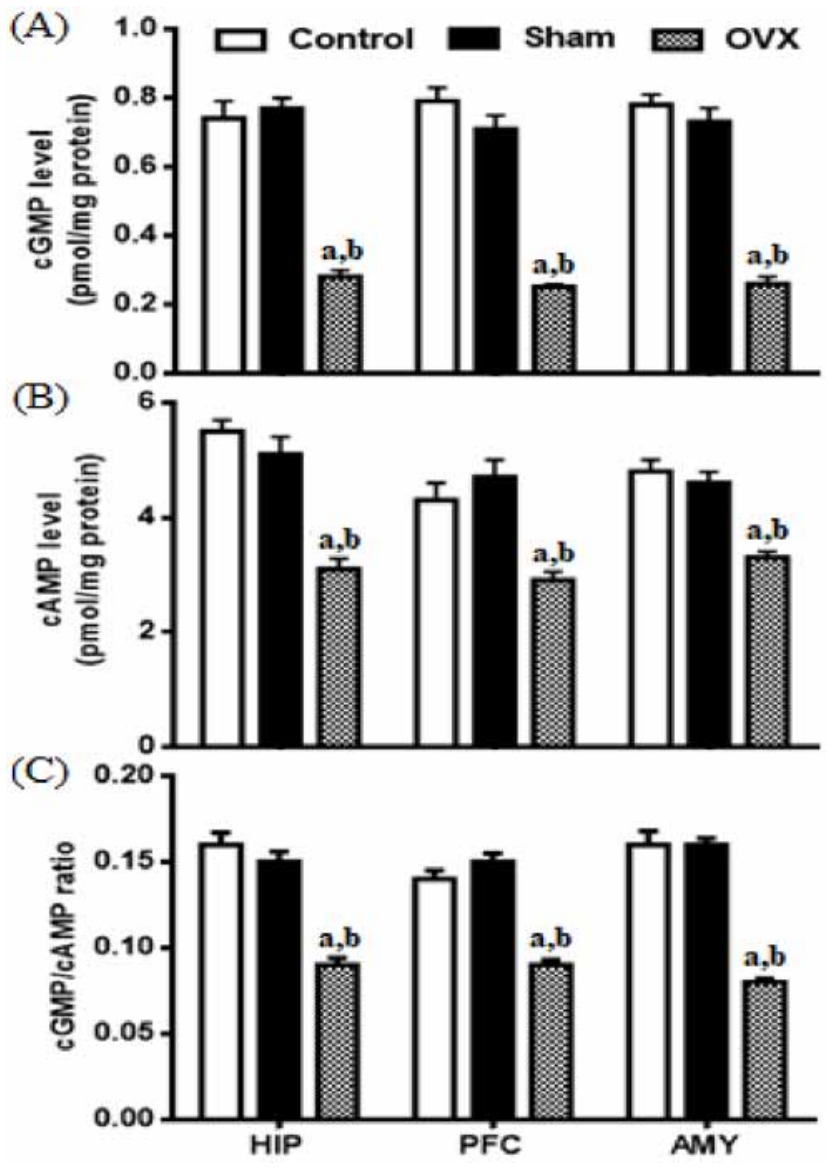

Figure 6: Effect of bilateral ovariectomy-induced changes in the level of cGMP (A), cAMP (B) and their ratio cGMP/cAMP (C) in rat HIP, PFC and AMY. All values are expressed in mean \pm SEM $(n=6)$. ${ }^{a} P<0.05$ as compared to Control, ${ }^{b} P<0.05$ as compared to Sham (One-way ANOVA followed by Student-Newmann-Keuls post hoc test).

nucleus in $\operatorname{HIP}([\mathrm{F}(2,6)=11.3, P<0.05]$ and $[\mathrm{F}(2,6)=9.2$, $P<0.05]$ respectively), $\operatorname{PFC}([\mathrm{F}(2,6)=12.1, P<0.05]$ and $[\mathrm{F}(2,6)=8.7, P<0.05]$ respectively) and $\mathrm{AMY}$ $([\mathrm{F}(2,6)=11.9, P<0.05]$ and $[\mathrm{F}(2,6)=9.3, P<0.05]$ respectively) among groups. Post-hoc test revealed that the extent of phosphorylation of $E R \alpha$ receptor in cytoplasm and translocation of $\mathrm{p}-\mathrm{ER} \alpha$ receptor in the nucleus of tissues of all the rat brain regions was significantly lower in OVX rats compared to control and sham group animals.

\section{Correlation analysis between cyclic nucleotides (cGMP/cAMP) and nuclear p-ER $\alpha / \mathrm{H} 3$}

Figure 8 illustrates the correlation between ratio of cyclic nucleotides (cGMP/cAMP) and nuclear p-ER $\alpha$ with respect to $\mathrm{H} 3$ in $\mathrm{HIP}(\mathrm{A}), \mathrm{PFC}(\mathrm{B})$ and AMY (C) of the animals. A significant positive correlation in HIP $\left(r^{2}=0.87\right.$, Pearson's $\left.r=0.93\right)$, PFC $\left(r^{2}=0.89\right.$, Pearson's $r=0.95)$ and AMY $\left(r^{2}=0.90\right.$, Pearson's $\left.r=0.95\right)$ were observed between the two parameters.

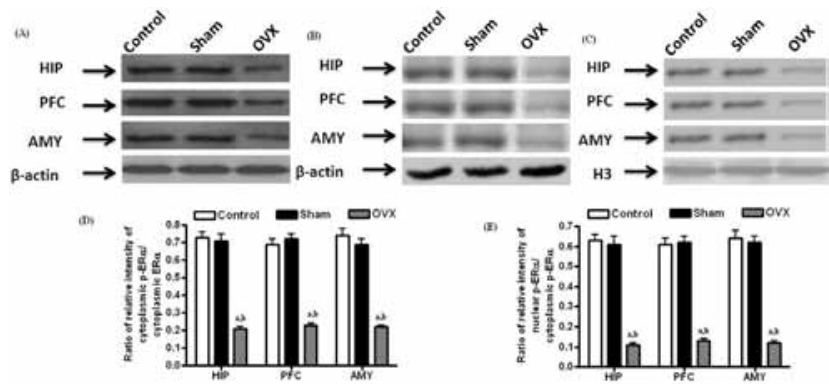

Figure 7: Effect of bilateral ovariectomy-induced changes in the extent of phosphorylation of ER $\alpha$ receptor in cytoplasm and translocation of $\mathrm{p}-\mathrm{ER} \alpha$ receptor in the nucleus of rat HIP, PFC and AMY tissues. Blots are representative of cytoplasmic $E R \alpha(A)$, cytoplasmic $p-E R \alpha(B)$ and nucleus $p-E R \alpha(C)$ of rat HIP, PFC and AMY. The results in the histogram (D) are expressed as the ratio of the relative intensity of cytoplasmic $p$-ER $\alpha /$ cytoplasmic $E R \alpha$ and (E) are expressed as the ratio of the relative intensity of nuclear $\mathrm{p}$-ER $\alpha /$ cytoplasmic $\mathrm{p}$-ER $\alpha$. All values are expressed in mean \pm SEM $(n=6)$. ${ }^{\text {a }} P<0.05$ as compared to Control, ${ }^{\mathrm{b}} \mathrm{P}<0.05$ as compared to Sham (One-way ANOVA followed by Student-Newmann-Keuls post hoc test).

\section{DISCUSSION}

In the present study, we report that the bilateral ovariectomy significantly reduced the extent of phosphorylation and translocation of $\mathrm{ER} \alpha$ receptor in memory-sensitive brain areas of the rodents. Further, there was a significant reduction in the levels of cyclic nucleotides in memory-sensitive brain regions of these animals. Moreover, there was a significant positive correlation between the ratio of cyclic nucleotides (cGMP/cAMP) and nuclear p-ER $\alpha$ with respect to $\mathrm{H} 3$ in all the selected brain regions. These observations laid down the fact that there could be a direct relationship between the activity of ER $\alpha$ receptor and levels of cyclic nucleotides in the memory-sensitive brain regions of the animals subjected to bilateral ovariectomy. Our behavioral results suggest that bilateral ovariectomy caused a significant loss in learning and memory in the MWM test and impairment in spatial memory in the Y-maze test similar to earlier findings. ${ }^{33,34}$ These animals also exhibited a significant loss in cholinergic activity in terms of decreased ACh level and activity of ChAT and increased AChE activity in memory-sensitive brain regions. It has been well suggested that the circulating estrogen can interfere with cholinergic function through ER $\alpha$ in memory-sensitive brain regions. ${ }^{15}$ It has been reported that bilateral ovariectomy causes a significant reduction in the level of ER $\alpha$ in memory-sensitive brain regions of the animals. ${ }^{15}$ We report a significant reduction in the ratio of $\mathrm{ER} \alpha$ between phosphorylated to non-phosphorylated form in all brain regions. These observations indicate the fact that there may be a reduction in the extent of phosphorylation of ER $\alpha$. Previous 


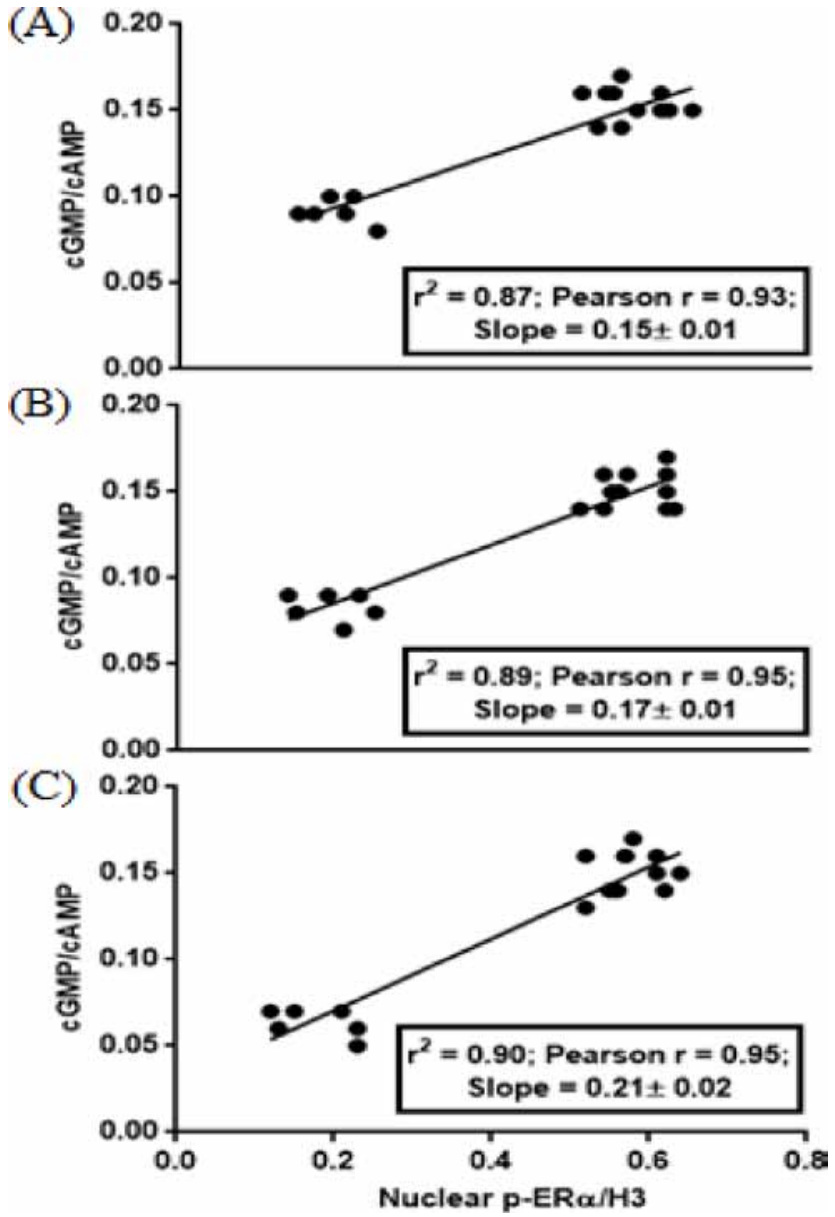

Figure 8: Illustrates the correlation between the ratio of cyclic nucleotides (cGMP/cAMP) and nuclear $p-E R \alpha$ with respect to $\mathrm{H} 3$ in the HIP (A), PFC (B) and AMY (C) of the animals [Pearson's correlational analysis at $P<0.05$ ].

reports suggest that phosphorylated $\mathrm{ER} \alpha$ plays a similar role as that of liganded $\mathrm{ER} \alpha$ in modulating cellular function in brain. ${ }^{10-12}$ In the present study, we report a significant decrease in the ratio of phosphorylated ER $\alpha$ between nuclear and cytoplasmic fractions of the brain tissues. These observations could either be attenuation in the extent of phosphorylation or defect in the import signals of $\mathrm{ER} \alpha$ to the nucleus in all memory-sensitive brain regions. Thus, it can be assumed that there is also impairment in the phosphorylated ER $\alpha$ activity in memory-sensitive brain regions during estrogen deficiency.

In cholinergic neurons, the 4-estren-3 $\alpha, 17 \beta$-diol (estren), a non-classical estradiol pathway activator, phosphorylates c-AMP-response-element-binding-protein and extracellular-signal-regulated-kinase- $1 / 2$ probably through $\mathrm{ER} \alpha$ activity in memory-sensitive brain regions of $A \beta_{1-42}$ administered dementia rats. ${ }^{35}$ Grisomm and Denial $^{36}$ also report that insulin-like growth factor-1 promotes the phosphorylation of ER $\alpha$ in the hippocampus and thus encourage memory formation in ovariectomized rats. Other studies further support the fact that endogenous substances such as growth factors of peptide, insulin and neurotransmitters like dopamine enhance the activity of $\mathrm{ER} \alpha$ in memory-sensitive brain regions. Most of these studies indicate cross-talk between peptide growth factor, insulin growth factor and neurotransmitters such as dopamine through kinase activity, not through increasing the level of cyclic nucleotides. ${ }^{12,36-38}$ Moreover, it has been documented that cyclic nucleotides promote the phosphorylation of $\mathrm{ER} \alpha$ in brain tissues suggesting that cyclic nucleotides are important mediators in the mechanism of estrogen through ER $\alpha$ receptor activity. ${ }^{38,39}$ Our present study reports that there was a significant loss in the level of cyclic nucleotides such as cAMP and cGMP in all memory-sensitive brain regions of ovariectomized rodents. It has also been suggested that GSK-3 beta inhibitors can promote the phosphorylation of $\mathrm{ER} \alpha$ at Ser-118 site, which can improve the memory function in ovariectomized animals. ${ }^{34}$ Taken into consideration the above facts, it can be assumed that cyclic nucleotides could be one of the targets to promote the ligandindependent mechanism of estrogen through ER $\alpha$ receptor activity during memory formation in estrogen deficiency condition which mechanism has to be established with future studies. Further, the present study demonstrated for the first time that there was a significant positive correlation between ratio of cyclic nucleotides (cGMP/cAMP) and nuclear p-ER $\alpha$ with respect to $\mathrm{H} 3$ in the selected brain regions indicating the fact that there could be a direct relationship between ratio of cyclic nucleotides and activity of phosphorylated $\mathrm{ER} \alpha$ receptor during such condition.

\section{CONCLUSION}

In conclusion, bilateral ovariectomy impairs phosphorylation of $\mathrm{ER} \alpha$ and translocation of phosphorylated $\mathrm{ER} \alpha$ receptor in memory-sensitive brain regions of the rodents indicating impairment in the phosphorylated $\mathrm{ER} \alpha$ receptor activity. Further, the levels of cyclic nucleotides are reduced in memory-sensitive brain regions of these animals. Therefore, the results suggest that there could be a direct relationship between phosphorylated $E R \alpha$ receptor activity and levels of cyclic nucleotides in the memory-sensitive brain regions of ovariectomized animals. Hence, it can be assumed that cyclic nucleotides could be a potential and alternate target to promote the phosphorylation of ER $\alpha$ receptormediated activity of estrogen during memory formation in estrogen deficiency condition. 


\section{ACKNOWLEDGEMENT}

The authors are thankful to GLA University, Mathura, Uttar Pradesh, India for the financial assistantship.

\section{CONFLICT OF INTEREST}

The authors declare that they have no conflict of interests.

\section{ABBREVIATIONS}

AD: Alzheimer's Disease; ER $\alpha$ : Estrogen Receptor Alpha; ERE: Estrogen Response Elements; cAMP: Cyclic Adenosine Monophosphate; cGMP: Cyclic Guanosine Monophosphate; p-ER $\alpha$ : Phosphorylated Estrogen Receptor Alpha; OVX: Ovariectomy; HIP: Hippocampus; PFC: Pre-frontal Cortex; AMY: Amygdala; MWM: Morris Water Maze; SAB: Spontaneous Alteration Behaviour; ChAT: Choline Acetyltransferase; Ach: Acetylcholine; AChE: Acetylcholinesterase; CPCSEA: Committee for the Purpose of Control and Supervision of Experiments on Animals; H3: Histone-3; ECL: Enhanced Chemiluminescence; ANOVA: Analysis of Variance.

\section{REFERENCES}

1. Lam RW, Kennedy SH, McIntyre RS, Khullar A. Cognitive dysfunction in major depressive disorder: Effects on psychosocial functioning and implications for treatment. Can J Psychiatry. 2014;59(12):649-54.

2. Weintraub $S$, Wicklund $A H$ and Salmon DP. The neuropsychological profile of Alzhemier disease. Cold Spring Harb Perspect Med. 2012;2(4):1-18.

3. Ferri CP, Prince M, Brayne C, Brodaty $H$, Fratiglioni L, Ganguli M, et al. Alzheimer's Disease International, Global prevalence of dementia: A Delphi consensus study. Lancet. 2005;366(9503):2112-7.

4. Carter CL, Resnick EM, Mallampalli M, Kalbarczyk A. Sex and gender differences in Alzheimer's disease: Recommendations for future research. J Women's Health. 2012;21(10):1018-23.

5. Jamshed N, Ozair FF, Aggarwal P, Ekka M. Alzheimer disease in postmenopausal women: Intervene in critial window period. J Mislife Health. 2014;5(1):38-40.

6. Bonomo SM, Rigamonti AE, Giunta M, Galimberti D, Guaita A, Gagliano MG, et al. Menopausal transition: A possible risk factor for brain pathologic events. Neurobiol Aging. 2009;30(1):71-80.

7. Daniel JM, Bohacek J. The critical period hypothesis of estrogen effects on cognition: Insights from basic research. Biochim Biophys. 2010;1800(10):1068-76.

8. Schupf N, Lee JH, Wei M, Pang D, Chace C, Cheng R, et al. Estrogen receptor- $\alpha$ variants increase risk of Alzheimer's disease in women with down syndrome. Dement Geriatr Cogn Disord. 2008;25(5):476-82.

9. Yasar P, Ayaz G, User SM, Gupur G, Muyan M. Molecular mechanism of estrogen-estrogen receptor signaling. Reprod Med Biol. 2017;16(1):4-20.

10. Hall JM, Couse JF, Korach KS. The multifaceted mechanisms of estradiol and estrogen receptor signaling. J Biol Chem. 2001;276(40):36869-72.

11. Kushner PJ, Agard D, Feng WJ, Lopez G, Schiau A, Uht R, et al. Oestrogen receptor function at classical and alternative response elements. Novartis Found Symp. 2000;230:20-40.

12. Kato $\mathrm{S}$, Endoh $\mathrm{H}$, Masuhiro $\mathrm{Y}$, Kitamoto $\mathrm{T}$, Uchiyama $\mathrm{S}$, Sasaki $\mathrm{H}$, et al. Activation of the estrogen receptor through phosphorylation by mitogenactivated protein kinase. Science. 1995;270(5241):1491-4.
13. Ishunina TA, Fischer DF, Swaab DF. Estrogen receptor $\alpha$ and its splice variants in the hippocampus in aging and Alzheimer's disease. Neurobiol Aging. 2007;28(11):1670-81.

14. Perlman WR, Tomaskovic-Crook E, Montague DM, Webster MJ, Rubinow DR, Kleinman JE, et al. Alteration in estrogen receptor a mRNA levels in frontal cortex and hippocampus of patients with major mental illness. Biol Psychiatry. 2005;58(10):812-24

15. Qu N, Wang L, Liu ZC, Tian Q, Zhang Q. Oestrogen receptor a agonist improved long-term ovariectomy-induced spatial cognition deficit in young rats. Int J Neuropsychopharmacol. 2013;16(5):1071-82.

16. Cardoso CC, Ricardo VP, Frussa-Filho R, Porto CS, Abdalla FM. Effects of $17 \beta$-estradiol on expression of muscarinic acetylcholine receptor subtypes and estrogen receptor $\alpha$ in rat hippocampus. Eur J Pharmacol. 2010;634(13):192-200.

17. Szego EM, Barabas K, Balog J, Szilagyi N, Korach KS, Juhasz G, et al. Estrogen induces estrogen receptor-dependent camp response elementbinding protein phosphorylation via mitogen-activated protein kinase pathway in basal forebrain cholinergic neurons in vivo. J Neurosci. 2006;26(15):4104-10.

18. Neve KA, Seamans JK, Trantham-Davidson H. Dopamine receptor signaling. J Recept Signal Transduct Res. 2004;24(3):165-205.

19. Sharma S, Kumar K, Deshmukh R, Sharma PL. Phosphodiesterases: Regulators of cyclic nucleotide signals and novel molecular target for movement disorders. Eur J Pharmacol. 2013;714(1-3):486-97.

20. Delghandi MP, Johannessen $M$, Moens $U$. The cAMp signalling pathway activates CREB through PKA, p38 and MSK1 in NIH 3T3 cells. Cell Signal. 2005;17(11):1343-51.

21. Puerta E, Hervias I, Barros-Miñones L, Jordan J, Ricobaraza A, CuadradoTejedor M, et al. Sildenafil protects against 3-nitropropionic acid neurotoxicity through the modulation of calpain, CREB and BDNF. Neurobiol Dis. 2010;38(2):237-45.

22. Cao X, Zhou C, Chong J, Fu L, Zhang L, Sun D, et al. Estrogen resisted stress-induced cardiomyopathy through increasing the activity of $\beta 2 A R-G a s$ signal pathway in female rats. Int J Cardiol. 2015;187:377-86.

23. Sagredo A, DelCampo L, Martorell A, Navarro R, Martin MC, Blanco-Rivero J, et al. Ovariectomy increases the participation of hyperpolarizing mechanisms in the relaxation of rat aorta. PLoS One. 2013;8(9):e73474.

24. Nathanson NM. A mutiplicity of muscrinic mechanisms: Enough signaling pathways to take your breath away. Proc Natl Acad Sci USA. 2000;97(12):6245-7.

25. Palkovits M, Brownstein MJ. Maps and guide to microdissection of the rat brain. Elsevier, New York. 1988.

26. Morris R. Developments of a water-maze procedure for studying spatial learning in the rat. J Neurosci Methods. 1984:11(1):47-60.

27. Sharma B, Singh N. Defensive effect of natrium diethyldithiocarbamate trihydrate (NDDCT) and lisinopril in DOCA-salt hypertension-induced vascular dementia in rats. Psychopharmacology. 2012;223(3):307-17.

28. Mouri A, Noda $Y$, Hara $H$, Mizoguchi H, Tabira T, Nabeshima T. Oral vaccination with a viral vector containing a cDNA attenuates age-related a accumulation and memory deficits without causing inflammation in a mouse Alzheimer model. FASEB J. 2007;21(9):2135-48.

29. Muthuraju S, Maiti PS, Sharma AK, Amitabh SSB, Prasad D, Ilavazhagan G. Acetylcholinesterase inhibitors enhance cognitive functions in rats following hypobaric hypoxia. Behav Brain Res. 2009;203(1):1-14.

30. Zoukhri D, Kublin CL. Impaired neurotransmitter release from lacrimal and salivary gland nerves of a murine model of Sjogren's syndrome. Invest Ophthalmol Vis Sci. 2001;42(5):925-32.

31. Lowry $\mathrm{OH}$, Rosebrough NJ, Farr AL, Randall RJ. Protein measurement with the folin phenol reagent. J Biol Chem. 1951;193(1):265-75.

32. Bradford MM. A rapid and sensitive method for the quantitation of microgram quantities of protein utilizing the principle of protein-dye binding. Anal Biochem. 1976;72:248-54.

33. Hawley WR, Grissom EM, Moody NM, Dohanich GP, Vasudevan N. Activation of G-protein-coupled receptor 30 is sufficient to enhance spatial recognition memory in ovariectomized rats. Behav Brain Res. 2014;262:68-73.

34. Qu N, Zhou XY, Han L, Wang L, Xu JX, Zhang T, et al. Combination of PPT with $\mathrm{LiCl}$ treatment prevented bilateral ovariectomy-induced hippocampaldependent cognition deficit in rats. Mol Neurobiol. 2016;53(2):894-904. 
Kwakowsky A, Potapov K, Kim S, Peppercorn K, Tate WP, Abraham IM. Treatment of beta-amyloid 1-42 (Aß1-42)-induced basal forebrain cholinergic damage by a non-classical estrogen signaling activator in vivo. Sci Rep. 2016;6:21101.

36. Grissom EM, Daniel JM. Evidence for ligand-independent activation of hippocampal estrogen receptor- $\alpha$ by igf-1 in hippocampus of ovariectomized rats. Endocrinology. 2016;157(8):3149-56.

37. Ignar-Trowbridge DM, Pimentel M, Parker MG, McLachlan JA, Korach KS. Peptide growth factor cross-talk with the estrogen receptor requires the $\mathrm{a} / \mathrm{b}$ domain and occurs independently of protein kinase $\mathrm{c}$ or estradiol. Endocrinology. 1996;137(5):1735-44.

38. Power RF, Mani SK, Codina J, Conneely OM, O'Malley BW. Dopaminergic and ligand-independent activation of steroid hormone receptors. Science. 1991;254(5038):1636-9.

39. Aronica SM, Katzenellenbogen BS. Stimulation of estrogen receptormediated transcription and alteration in the phosphorylation state of the rat uterine estrogen receptor by estrogen, cyclic adenosine monophosphate and insulin-like growth factor-I. Mol Endocrinol. 1993;7(6):743-52.

\section{PICTORIAL ABSTRACT}

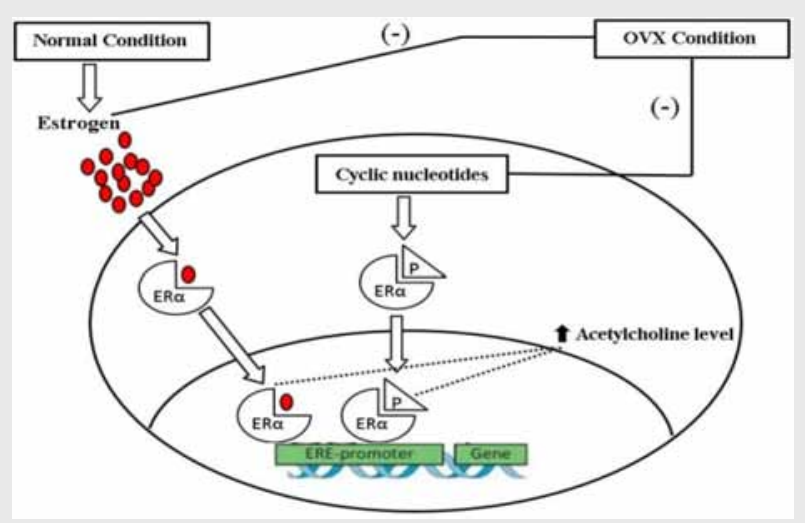

About Authors

\section{SUMMARY}

- In the present study, bilateral ovariectomy impairs phosphorylation of $\mathrm{ER} \alpha$ and translocation of phosphorylated $\mathrm{ER} \alpha$ receptor in memory-sensitive brain regions of the rodents indicating impairment in the phosphorylated $\mathrm{ER} \alpha$ receptor activity.

- Further, the levels of cyclic nucleotides were estimated in those brain regions to draw a possible correlation on phosphorylated $\mathrm{ER} \alpha$ signaling.

- The levels of cyclic nucleotides found to be reduced in memory-sensitive brain regions of these animals. Therefore, the results suggest that there could be a direct relationship between phosphorylated ER $\alpha$ receptor activity and levels of cyclic nucleotides in the memory-sensitive brain regions of ovariectomized animals.

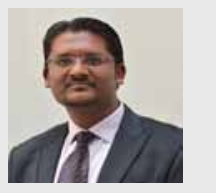

Mr. Ahsas Goyal is currently serving as Assistant Professor in Department of Pharmacology, Institute of Pharmaceutical Research, GLA University, Mathura. He has more than 5 years of teaching experience after successful completion of M. Pharm. (Pharmacology). He considers neuropharmacology as research topic in his Ph.D. work. Moreover, he is also having experience in the field of cardiovascular pharmacology as part of academic research activities. He is resourceful contributor of research papers in journals of national and international repute.

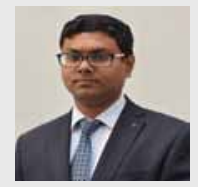

Dr. Debapriya Garabadu is currently working as Associate Professor in Department of Pharmacology, Institute of Pharmaceutical Research, GLA University, Mathura. He did his M. Pharm. (Pharmacology) and Ph.D. from Indian Institute of Technology (Banaras Hindu University). He has more than 10 years of teaching experience and is actively engaged in neuropsychopharmacology research. He is resourceful contributor of more than 50 research papers in journals of national and international repute.

Cite this article: Goyal A, Garabadu D. Bilateral Ovariectomy Decreases the Levels of Cyclic Nucleotides and Nuclear Phosphorylated Estrogen Receptor-Alpha in Memory-Sensitive Rat Brain Regions. Indian J of Pharmaceutical Education and Research. 2020;54(1):125-34. 